Corrigendum

\title{
Corrigendum to "Pain Relieving Effect of Intraoperative Chemical Splanchnicectomy of Celiac Ganglions in Patients with Resectable Pancreatic or Gastric Masses: A Randomized Clinical Trial”
}

\author{
Jalal Vahedian, ${ }^{1}$ Amir Saraee, ${ }^{1}$ Massoud Baghai Wadji ${ }^{10},{ }^{1}$ Paniz Motaghi, ${ }^{1}$ Kia Vosoughi, \\ Saeed Safari, ${ }^{1}$ and Abdolhamid Chavoshi Khamneh $\mathbb{1}^{2}$ \\ ${ }^{1}$ Iran University of Medical Sciences, Firoozgar Hospital, Tehran, Iran \\ ${ }^{2}$ Tehran University of Medical Sciences, Shariati Hospital, Tehran, Iran \\ Correspondence should be addressed to Abdolhamid Chavoshi Khamneh; chavoshikhamneh.ah@gmail.com \\ Received 7 February 2021; Accepted 7 February 2021; Published 26 February 2021
}

Copyright ( $\odot 2021$ Jalal Vahedian et al. This is an open access article distributed under the Creative Commons Attribution License, which permits unrestricted use, distribution, and reproduction in any medium, provided the original work is properly cited.

\begin{abstract}
In the article titled "Pain Relieving Effect of Intraoperative Chemical Splanchnicectomy of Celiac Ganglions in Patients with Resectable Pancreatic or Gastric Masses: A Randomized Clinical Trial" [1], two authors were mistakenly omitted from the author list. The corrected author list and affiliations are given above.
\end{abstract}

\section{References}

[1] J. Vahedian, A. Saraee, M. Baghai Wadji, S. Safari, and A. Chavoshi Khamneh, "Pain Relieving Effect of Intraoperative Chemical Splanchnicectomy of Celiac Ganglions in Patients with Resectable Pancreatic or Gastric Masses: A Randomized Clinical Trial," Pain Research and Management, vol. 2020, Article ID 2675940, 6 pages, 2020. 